\title{
Influence of ice particle model on satellite ice cloud retrieval: lessons learned from MODIS and POLDER cloud product comparison
}

\author{
Z. Zhang ${ }^{1,2}$, P. Yang ${ }^{1}$, G. Kattawar ${ }^{3}$, J. Riedi ${ }^{4}$, L. C.-Labonnote ${ }^{4}$, B. A. Baum ${ }^{5}$, S. Platnick ${ }^{6}$, and H.-L. Huang ${ }^{5}$ \\ ${ }^{1}$ Department of Atmospheric Sciences, Texas A\&M University, College Station, TX, USA \\ ${ }^{2}$ Goddard Earth Sciences and Technology Center, University of Maryland at Baltimore County, Baltimore, MD, USA \\ ${ }^{3}$ Department of Physics, Texas A\&M University, College Station, TX, USA \\ ${ }^{4}$ Laboratoire d'Optique Atmosphérique - Université des Sciences et Technologies de Lille/CNRS, \\ Villeneuve d'Ascq Cedex, France \\ ${ }^{5}$ Space Science and Engineering Center - University of Wisconsin-Madison, Madison, WI, USA \\ ${ }^{6}$ NASA Goddard Space Flight Center, Greenbelt, MD, USA
}

Received: 31 October 2008 - Published in Atmos. Chem. Phys. Discuss.: 20 January 2009

Revised: 20 May 2009 - Accepted: 21 July 2009 - Published: 24 September 2009

\begin{abstract}
The influence is investigated of the assumed ice particle microphysical and optical model on inferring ice cloud optical thickness $(\tau)$ from satellite measurements of the Earth's reflected shortwave radiance. Ice cloud $\tau$ are inferred, and subsequently compared, using products from MODIS (MODerate resolution Imaging Spectroradiometer) and POLDER (POLarization and Directionality of the Earth's Reflectances). POLDER $\tau$ values are found to be substantially smaller than those from collocated MODIS data. It is shown that this difference is caused primarily by the use of different ice particle bulk scattering models in the two retrievals, and more specifically, the scattering phase function. Furthermore, the influence of the ice particle model on the derivation of ice cloud radiative forcing (CRF) from satellite retrievals is studied. Three sets of shortwave CRF are calculated using different combinations of the retrieval and associated ice particle models. It is shown that the uncertainty associated with an ice particle model may lead to two types of errors in estimating CRF from satellite retrievals. One stems from the retrieval itself and the other is due to the optical properties, such as the asymmetry factor, used for CRF calculations. Although a comparison of the CRFs reveals that these two types of errors tend to cancel each other, significant differences are still found between the three CRFs, which indicates that the ice particle model affects not
\end{abstract}

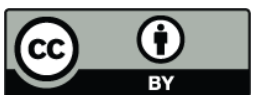

Correspondence to: Z. Zhang

(zzbatmos@umbc.edu) only optical thickness retrievals but also CRF calculations. In addition to CRF, the effect of the ice particle model on the derivation of seasonal variation of $\tau$ from satellite measurements is discussed. It is shown that optical thickness retrievals based on the same MODIS observations, but derived using different assumptions of the ice particle model, can be substantially different. These differences can be divided into two parts. The first-order difference is mainly caused by the differences in the asymmetry factor. The second-order difference is related to seasonal changes in the sampled scattering angles and therefore dependent on the sun-satellite viewing geometry. Because of this second-order difference, the use of different ice particle models may lead to a different understanding of the seasonal variation of $\tau$.

\section{Introduction}

Ice clouds cover about $20 \%$ of the Earth's surface (Wang et al., 1996; Wylie and Menzel, 1999; Sassen et al., 2008). They interact strongly with both solar and infrared radiation fields, and therefore can exert a significant influence on the radiative energy budget and thermal structure of the Earth-atmosphere system (Liou, 1986; Ramaswamy and Ramanathan, 1989; Fu and Liou, 1993; Lohmann and Roeckner, 1995). However, our understanding of this role is still limited. The current generation of climate models exhibits a large range in ice cloud climatology and radiative forcing estimates (Zhang et al., 2005). The magnitude of cloud

Published by Copernicus Publications on behalf of the European Geosciences Union. 
feedbacks remains very uncertain (Bony et al., 2006). The need for a better understanding of ice clouds is evident. To meet this need, continuous global observations of ice clouds from satellite-based instruments are indispensable.

Despite the substantial efforts and significant progress made over the last decade, reliable retrieval of ice cloud properties from remotely sensed measurements still remains a challenge owing to the complex nature of ice cloud particles. As revealed by the photos of ice particles, their sizes range from microns to millimeters and their habits (or shapes) vary from simple pristine hexagonal columns and plates to highly irregular aggregates and polycrystals (Weickmann, 1947; Heymsfield et al., 2002; Heymsfield, 2003). This makes the development of ice particle models that quantitatively replicate the microphysical and associated optical properties of ice particles very difficult. Over the last two decades, several major ice cloud measurement campaigns have been carried out (Cox et al., 1987; Jensen et al., 2004; Gallagher et al., 2005). Based on the in-situ and remotely-sensed data obtained from these campaigns, a number of ice particle models have been developed and used for ice cloud retrievals (e.g., McFarquhar and Heymsfield, 1996; C.-Labonnote et al., 2000; Baran et al., 2001; McFarquhar, 2001; McFarquhar et al., 2002; Baum et al., 2005; Baran and Labonnote, 2007). Unfortunately, as will be shown hereafter, these models generally differ substantially from one another. This indicates the existence of large uncertainty in ice cloud retrievals associated with ice particle model. Although the effect of this uncertainty depends on what kind of ice cloud property is retrieved and the method used for retrieval, it is usually an important source of error in ice cloud retrievals (Comstock et al., 2007).

Optical thickness $(\tau)$ is one of the most important radiative properties of clouds. It plays a key role in determining cloud radiative forcing (CRF) (e.g., Fu and Liou, 1993; Jensen et al., 1994; Fu, 1996; Fu et al., 1998; McFarquhar et al., 2000). A popular method to retrieve cloud $\tau$ relies on satellite measurements of the Earth's reflected shortwave radiance (King, 1987; Nakajima and King, 1990; Minnis et al., 1993) (Hereafter it is referred to as the "solar reflective method"). It has been employed in the retrieval algorithms of several satellite instruments, such as the Advanced Very High Resolution Radiometer (AVHRR) (Heidinger et al., 2005), Spinning Enhanced Visible and Infrared Imager (SEVIRI) (Roebeling et al., 2006), MODIS (Platnick et al., 2003) and POLDER (Buriez et al., 2005). The future Visible Infrared Imaging Radiometer Suite (VIIRS) that will fly on NPOESS (National Polar-Orbiting Environmental Satellite System) (Miller et al., 2006) and the Advanced Baseline Imager planed to fly on the Geostationary Operational Environmental Satellite-R Series (GOES-R) (Schmit et al., 2005) may also adopt this method for their operational cloud $\tau$ retrievals. Cloud products from these sensors will continue the satellite record useful for climate studies.
Although the principle behind the "solar reflective method" is simple (i.e., the cloud reflectance varies with optical thickness in the shortwave region), many factors may influence the retrievals results. For example, several studies have shown that the use of different ice particle models in the method might lead to substantially different retrieval results (Mishchenko et al., 1996; Baran et al., 1999; Knap et al., 2005; Yang et al., 2007, 2008). In addition, the spatial resolution, the characteristics of instrument and the implementation of the algorithm may also influence the retrieval. As a result, different satellite sensors may produce different $\tau$ retrievals for the same cloud. Such differences complicate our understanding of the climatic role of ice clouds due to the fact that satellite retrievals are now widely used, for example, to derive cloud climatologies (Rossow and Schiffer, 1999; Karlsson, 2003) and compare with GCM simulations (Zhang et al., 2005). Therefore, a study of the influences of the above factors, especially the ice particle model in ice cloud $\tau$ retrieval would help us to understand the differences of ice $\tau$ retrievals from different sensors and may improve our understanding of ice clouds. Moreover, such a study may also provide some guidance for establishing a long-term climatology of ice cloud $\tau$ from the retrievals provided by different satellite sensors.

Motivated by the above considerations, the primary objective of this study is to investigate the influence of ice particle model on ice cloud $\tau$ retrieval in comparison with other factors. To achieve this goal, we compare the collocated retrievals from the MODIS-Aqua and the POLDER onboard PARASOL. We address the following questions through the comparison. How different is the operational MODIS ice cloud $\tau$ retrieval from that of POLDER? What are the possible reasons for the differences? What is the influence of ice particle model? We will also discuss the potential implications for climate studies. We ask the questions: How, and to what extent, does the uncertainty associated with ice particle model impact our understanding of the climatology and radiative effects of ice clouds?

This paper is organized as follows. In Sect. 2 we discuss the differences between MODIS and POLDER ice cloud $\tau$ retrieval algorithms, with a special emphasis on the difference in ice particle models. In Sect. 1.2 we first compare the MODIS and POLDER ice cloud $\tau$ retrieval and then investigate the role of ice particle model among other reasons in causing the difference. Potential implications for climate studies are discussed in Sect. 2 and the paper is summarized in Sect. 5.

\subsection{MODIS and POLDER ice optical thickness retrieval algorithms}

As mentioned in the introduction, both MODIS and POLDER use a solar reflective method for their operational cloud $\tau$ retrieval. Specifically, the bands centered around $0.86-\mu \mathrm{m}$ (hereafter referred to as the " $0.86-\mu \mathrm{m}$ band") are 
used in both algorithms for retrieval over ocean. The bidirectional cloud reflection function $(R)$ observed by satellites in the $0.86-\mu \mathrm{m}$ band is defined as follows (Liou, 2002):

$R\left(\tau, \omega, P_{11}, \theta_{0}, \theta_{v}, \phi_{v}-\phi_{0}\right)=\frac{\pi I\left(\theta_{v}, \phi_{v}\right)}{F_{0} \cos \left(\theta_{0}\right)}$,

where $\omega$ and $P_{11}$ are the bulk-scattering albedo and phase function of cloud particles, respectively; $\theta_{0}$ and $\phi_{0}\left(\theta_{v}\right.$ and $\left.\phi_{v}\right)$ are the zenith and azimuthal angles of solar incidence (satellite-viewing direction), respectively; $F_{0}$ denotes the solar flux density and $I$ denotes radiance observed by satellite. Based on Eq. (1), $\tau$ is retrieved in practice usually using a socalled look-up table (LUT) (King et al., 1997) that specifies the relationship between $R$ and $\tau$. Because ice absorption is minimal in the $0.86-\mu \mathrm{m}$ band, $\omega$ is essentially unity. As a result, for a given $\tau$ and sun-satellite-viewing geometry the LUT depends solely on $P_{11}$, which in turn depends sensitively on the microphysical properties of ice particles, such as their sizes and shapes. For this reason, the ice particle model has a significant influence on the retrieval.

An ice particle model advanced by Baum et al. (2005) (hereafter referred to as the "Baum05 model") is employed in the MODIS operational retrieval algorithm, while POLDER retrieval is based on a so-called IHM (Inhomogeneous Hexagonal Monocrystal) model (C.-Labonnote et al., 2001). The two models are substantially different in many aspects. First, the Baum05 model is based primarily on the use of insitu observations of ice particle sizes and habits to compute optical properties for a realistic ensemble of theoretical particles. The IHM model has been developed by comparing theoretical models to direct measurements of the average BRDF of ice clouds as observed by POLDER. Secondly, ice clouds may have different effective radii $\left(r_{e}\right)$ in the Baum05 model, while in the IHM model only one effective radius $(30 \mu \mathrm{m})$ is assumed for all ice clouds. Thirdly, ice particles are assumed to have similar shapes in the IHM model (i.e., hexagonal column with internal air bubbles). The Baum05 categorizes ice particles into six habits and uses a size-dependent habit distribution to simulate the variation of ice particle habits with size. For example, ice particles smaller than $60 \mu \mathrm{m}$ are assumed to be $100 \%$ droxtal, which has 20 facets and is designed to represent small quasi-spherical ice particles (Yang et al., 2003; Zhang et al., 2004), and a mixture of $15 \%$ bullet rosettes, $50 \%$ solid hexagonal columns and $35 \%$ hexagonal plates is assumed for particles within 60 to $1000 \mu \mathrm{m}$. The justification for this habit distribution lies in the consistency between the theoretically-derived ice water content and median mass diameter based on this habit distribution and the in situ measurements. Bearing in mind the high complexity of ice particle microphysics and the large observation uncertainties, the Baum05 habit distribution also agrees with the in situ observations, that small ice particles are often quasi-spherical and ice particle complexity generally increases with increasing size (Lawson et al., 2006; Lawson et al., 2008 and the references within). Finally, all ice particle habits in the Baum05

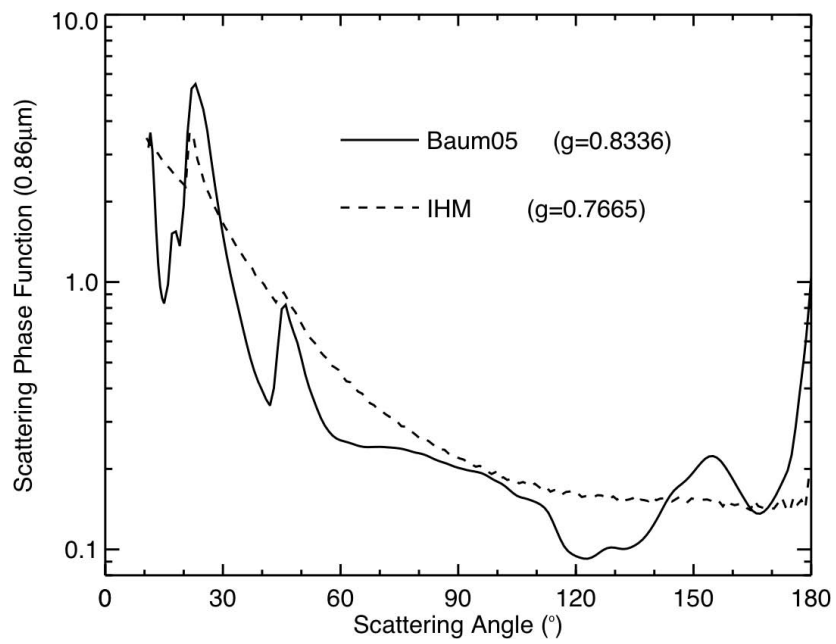

Fig. 1. The scattering phase functions from $10^{\circ}$ to $180^{\circ}$ and corresponding asymmetry factors of ice particles at $0.86-\mu \mathrm{m}$ according to the Baum05 model (solid line) and the IHM model (dashed line).

model have smooth surfaces and no inclusions of air bubbles, while the IHM model assumes that all ice particles contain many randomly distributed small air bubbles inside.

Because of the above differences in ice particle microphysics, the two models have substantially different $P_{11}$. Figure 1 shows the $P_{11}$ in the $0.86-\mu \mathrm{m}$ band based on the Baum05 model with $r_{e}=30 \mu \mathrm{m}$ (solid line) and the IHM model (dashed line) as a function of scattering angle. In the Baum05 $P_{11}$, several pronounced scattering features are clearly visible. At scattering angles between $0^{\circ}$ to $60^{\circ}$, which are particularly important for ground-based observations, the most marked features are the two sharp peaks around the $22^{\circ}$ and $46^{\circ}$ (i.e., the halos). In the region important for satellite-based and airborne instruments (i.e., from about $60^{\circ}$ to $180^{\circ}$ ), the features include a steep slope between about $120^{\circ}$ and $140^{\circ}$, a moderate scattering peak near $156^{\circ}$ and a sharp backscattering peak at $180^{\circ}$. Evidently from Fig. 1, the $P_{11}$ based on the IHM model is quite different. It is rather flat and featureless. Although the $22^{\circ}$ peak still exists, it is substantially weakened.

Another important difference between Baum05 and IHM model is in the asymmetry factor $(g)$, which indicates the ratio of forward-scattered to backward-scattered light (van de Hulst, 1957). Mathematically, $g$ is defined as follows (see for instance, Liou, 2002):

$g=\frac{1}{2} \int_{-1}^{1} P_{11}\left(\cos \theta_{s}\right) \cos \theta_{s} d \cos \theta_{s}$,

where $\theta_{s}$ is the scattering angle $\left(0<\theta_{s}<\pi\right)$. According to Baum05 model, the value of $g$ of an ice cloud with a $r_{e}$ of $30 \mu \mathrm{m}$ in the $0.86-\mu \mathrm{m}$ band is 0.8336 , while the corresponding value of the IHM model is 0.7665 . It is worth mentioning here that a large range of the values of the ice particle asymmetry factor in the solar spectral region can be found in the 
Table 1. The collocation resolutions and the resolutions of the MODIS and POLDER cloud products.

\begin{tabular}{llll}
\hline \multicolumn{4}{c}{ Level-1 collocation } \\
& $\begin{array}{l}\text { MODIS } \\
\text { product } \\
\text { (MOD021KM) }\end{array}$ & $\begin{array}{l}\text { POLDER } \\
\text { product } \\
(\text { L1-B) }\end{array}$ & Collocation \\
Resolution & $1 \times 1 \mathrm{~km}^{2}$ & $6 \times 6 \mathrm{~km}^{2}$ & $6 \times 6 \mathrm{~km}^{2}$ \\
\hline \multicolumn{5}{c}{ Level-2 collocation } \\
\hline
\end{tabular}

literature. The Baum05 (IHM) model is in the upper (lower) portion of this range. Interested readers are directed to (Jourdan et al., 2003 and the references within).

Since the differences between the two $P_{11}$ are substantial, it is worth explaining the physics causing such differences. Numerical scattering simulations have shown that scattering features, such as those in the Baum05 $P_{11}$, are generated by two or more photon reflections or refractions at the faces of hexagonal prisms (Takano and Liou, 1989). In the Baum05 model, a large portion of ice particles is assumed to be pristine hexagonal columns and plates. As a result, the scattering features associated with these particles, for example the $22^{\circ}$ and $46^{\circ}$ halos, remain pronounced even after averaging over the particle habit distribution. In the case of the IHM model, however, the interactions between the randomly distributed small air bubbles and incident photons make the paths of photons much less organized, which substantially reduces or even smoothes out the scattering peaks leading to a flat and featureless $P_{11}$ (C.-Labonnote et al., 2001). Air bubble inclusion also plays an important role in causing the difference in $g$ between the two models, for it is known that nonabsorbing inclusions, such as air bubbles, reduces forwardscattering and increases the side and back-scattering (Macke et al., 1996a). Both fractal and roughened surfaces can also have effects on the scattering properties of ice particles similar to air bubble inclusion, i.e., smoothing out scattering features and reducing the asymmetry factor (Macke et al., 1996b; Yang et al., 2008).

Besides the difference in the chosen ice particle model, MODIS and POLDER algorithms are also different in three major respects: First, MODIS retrieves cloud optical thickness at the resolution of $1 \times 1 \mathrm{~km}^{2}$ (Platnick et al., 2003). Although POLDER has a "full-resolution" of about $6 \times 6 \mathrm{~km}^{2}$, cloud optical thickness is retrieved at the resolution of "superpixel", which is about $18 \times 18 \mathrm{~km}^{2}$, composed of $3 \times 3$ fullresolution pixels (Buriez et al., 2005). In practice, radiances of $3 \times 3$ full-resolution pixels are first aggregated to the res- olution of superpixel and then cloud optical thickness corresponding to superpixels is retrieved on the basis of the aggregated radiance. The resolutions of MODIS and POLDER products involved in this study are listed in Table 1. Secondly, the wide spectral coverage of MODIS enables it to retrieve the $r_{e}$ of ice clouds from observations in the nearinfrared ice-absorbing bands, such as the 1.64 and $2.13 \mu \mathrm{m}$ bands, using the method developed by Nakajima and King (1990). In contrast, the spectral coverage of POLDER ranges from 0.443 to $0.910 \mu \mathrm{m}$. The absorption of ice in this region is weak, thus POLDER lacks the capability to provide an inference of $r_{e}$. This is the reason why all ice clouds are assumed to have the same $r_{e}$ of $30 \mu \mathrm{m}$ in the POLDER retrieval. Note that because $P_{11}$ and therefore cloud reflectance are dependent on $r_{e}$, the treatment of $r_{e}$ may impact $\tau$ retrieval. Finally, MODIS is a crosstrack scanner that makes observations, and therefore provides an inference of $\tau \mathrm{s}$ for a given pixel in a single direction (Platnick et al., 2003). However, POLDER performs measurements in multiple directions. It first retrieves cloud optical thickness in all available directions and then a directionally averaged optical thickness is derived from the multi-directional retrievals (Buriez et al., 2005).

\subsection{Comparison of ice cloud optical thickness}

In this section, we first compare the MODIS and POLDER ice cloud $\tau$ retrievals. Then, we investigate the relevance of differences in retrieval algorithms described in the last section to the differences in ice optical thickness revealed by the comparison.

\subsection{Case selection and collocation}

An Aqua MODIS granule over Central America on 22 July 2007 is selected for the comparison. Figure 2 shows the false-color image of this granule. The image was constructed by contrast stretching and combining three different MODIS bands assigned to red, green and blue channels (RGB), respectively. To obtain contrast between ocean, land, low-level water clouds and high-level ice clouds, the RGB assignment is as follows: reflectances in the $0.66-\mu \mathrm{m}$ and $0.86-\mu \mathrm{m}$ bands are in red and green, respectively and $11-\mu \mathrm{m}$ brightness temperature (gray flipped) is in blue. In this color scheme, ocean is dark; land surface is green; ice clouds generally have a whitish cast (although cirrus may appear bluish); and low-level water clouds appear somewhat yellowish green. Cloud evolution observations from geostationary satellites (not shown here) indicate that a deep convective system developed early to the south of Panama had dissipated, leaving behind the anvil clouds that cover the center of the granule. To the northeast of the anvils along the coast of Columbia is another convective system at its later stage. The granule in Fig. 2 is selected because it contains a variety of ice clouds, from thin cirrus at the edge of a deep convection system to 


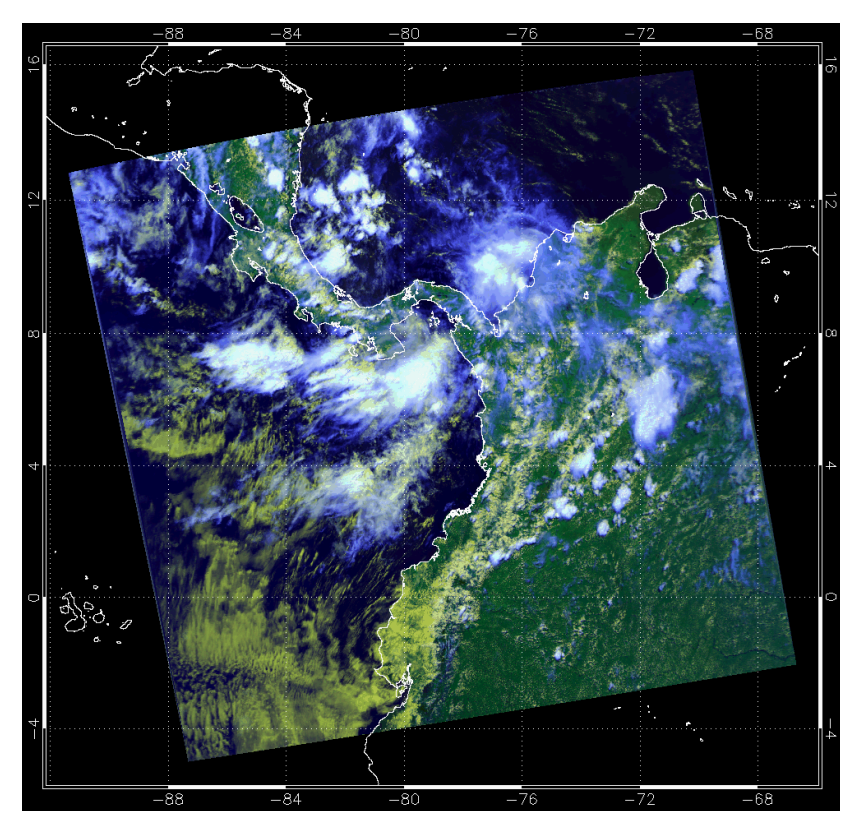

Fig. 2. The false-color image (Red: reflectance in $0.65-\mu \mathrm{m}$ band; Green: reflectance in 0.86- $\mu \mathrm{m}$ band; Blue: Brightness temperature of $11-\mu \mathrm{m}$ band after gray flopped) of the Aqua MODIS granule selected for comparison. In the image, ocean is dark, land is green, low level clouds appear yellowish and high level clouds are white or light blue.

thick anvils. Another consideration is that data from NASA's $\mathrm{TC}^{4}$ (Tropical Composition, Cloud and Climate Coupling) mission, which was conducted in July and August of 2007 over Central America, will provide valuable information for future study.

An important step before the comparison is the collocation of MODIS and POLDER retrievals. Both the level-2 operational cloud products and level-1 geolocated radiance products have been collocated using a data fusion system developed by Laboratoire d'Optique Atmospherique (France). The collocation is made at the POLDER full resolution $\left(6 \times 6 \mathrm{~km}^{2}\right)$. The resolutions of the MODIS and POLDER products involved in the collocation are listed in Table 1. The objective of the collocation is to obtain two sets of cloud properties or radiances for each collocated pixel, one corresponding to MODIS and the other corresponding to POLDER retrieval. Further details follow.

1) Level-1 radiance collocation. To collocate MODIS and POLDER level-1 geolocated radiance products, MODIS level-1 pixels $\left(1 \times 1 \mathrm{~km}^{2}\right)$ are first collocated to POLDER full resolution pixels $\left(6 \times 6 \mathrm{~km}^{2}\right)$. Then the radiances from MODIS pixels within each POLDER full resolution pixel are averaged to obtain a mean and standard deviation values for the collocation $\left(6 \times 6 \mathrm{~km}^{2}\right)$.

2) Level-2cloud product collocation. The level-2 collocation consists of two steps. In the first step, POLDER fullresolution pixels $\left(6 \times 6 \mathrm{~km}^{2}\right)$ are collocated to the POLDER

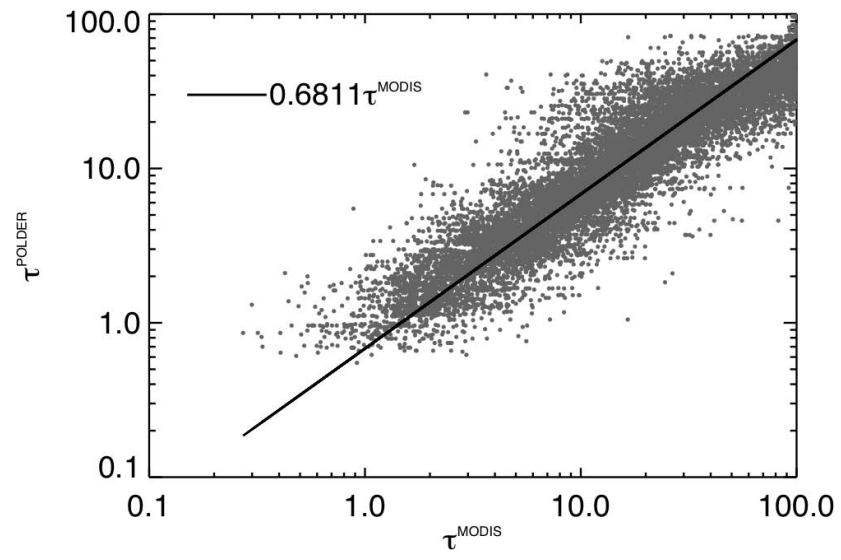

Fig. 3. Comparison of MODIS ( $\left.\tau^{\text {MODIS }}\right)$ and POLDER $\left(\tau^{\text {POLDER }}\right)$ ice cloud $\tau$ retrievals for the granule in Fig. 2. The solid line corresponds to a fitting of $\tau^{\text {POLDER }}$ with $0.6811 \tau^{\text {MODIS }}$.

super-pixels $\left(18 \times 18 \mathrm{~km}^{2}\right)$. Cloud properties from POLDER level-2 cloud product $\left(18 \times 18 \mathrm{~km}^{2}\right)$ are assigned each collocated full-resolution pixel. Note that, if two full-resolution pixels are within the same super-pixel, the same cloud properties will be assigned to them. This process can be seen as a nearest pixel extrapolation of level 2 products to level 1 resolution. In the second step, MODIS cloud $\tau$ retrievals $\left(1 \times 1 \mathrm{~km}^{2}\right)$ are first collocated to POLDER full-resolution pixels. Then, within each POLDER full-resolution pixel, cloud properties from MODIS cloud product are averaged over all MODIS pixels to obtain a new set of cloud properties. Therefore, after the collocation, each POLDER fullresolution pixel has two sets of cloud properties, one from POLDER RB2 and one from MODIS MOD06 cloud product. Note that the extrapolation of the POLDER RB2 product to full spatial resolution may introduce some random deviation for the comparison to MODIS products. However, it will not bias the correlation between the two datasets since average values are conserved.

The differences between MODIS and POLDER cloud top thermodynamic phase retrievals remain outside the scope of this study but interested readers are referred to Riedi et al. (2007). We choose only those pixels identified as ice clouds by both MODIS and POLDER for $\tau$ comparisons.

\subsection{Comparison results and discussion}

Figure 3 shows a scatterplot of pixel-to-pixel comparison of collocated MODIS ( $\left.\tau^{\text {MODIS }}\right)$ and POLDER ( $\left.\tau^{\text {POLDER }}\right)$ ice $\tau$ retrievals for the granule shown in Fig. 2. It is first noted from Fig. 3 that $\tau^{\text {MODIS }}$ is highly correlated with $\tau^{\text {POLDER }}$. However, it is evident that $\tau^{\text {POLDER }}$ is substantially smaller than $\tau^{\text {MODIS }}$. To understand the differences between $\tau^{\text {POLDER }}$ and $\tau^{\text {MODIS }}$ quantitatively, we calculated the probability density function (PDF) and the cumulative distribution of $\tau^{\text {POLDER }} / \tau^{\text {MODIS }}$. They are plotted as the solid lines in 


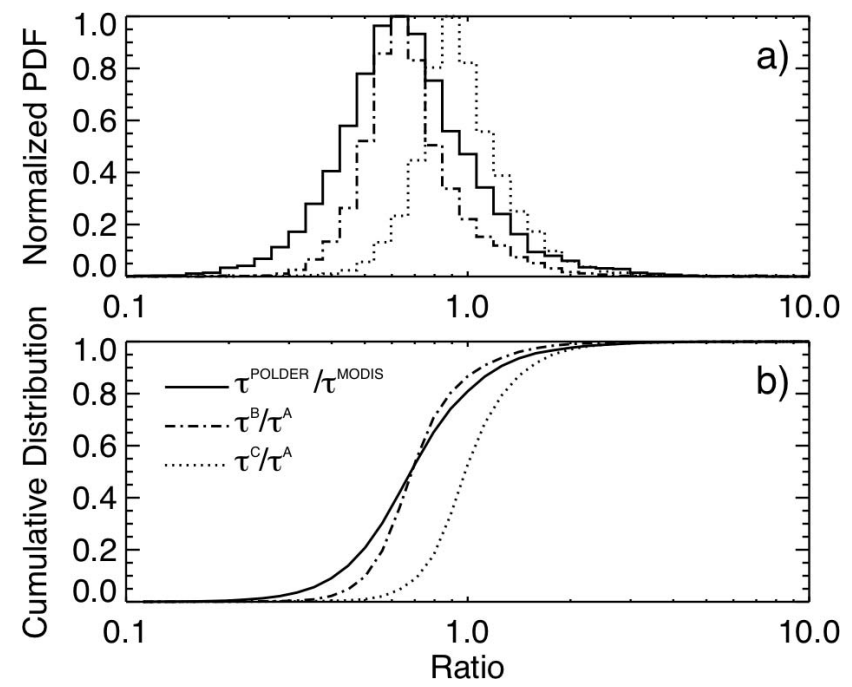

Fig. 4. (a) Normalized PDFs and (b) corresponding cumulative distributions of $\tau^{\text {POLDER }} / \tau^{\text {MODIS }}, \tau^{B} / \tau^{A}$ and $\tau^{C} / \tau^{A}$. The PDF is defined as the number of pixels with certain value of $\tau^{\text {POLDER }} / \tau^{\text {MODIS }}, \tau^{B} / \tau^{A}$ or $\tau^{C} / \tau^{A}$ divided by the number of the total pixels. For the sake of comparison, the PDFs are normalized to unity.

Fig. $4 \mathrm{a}$ and $\mathrm{b}$ respectively. The PDF of $\tau^{\mathrm{POLDER}} / \tau^{\text {MODIS }}$ is defined as the fraction of pixels with certain value of $\tau^{\text {POLDER }} / \tau^{\text {MODIS }}$. The maximum value of PDF has been normalized to unity. It is interesting to note that the PDF of $\tau^{\text {POLDER }} / \tau^{\text {MODIS }}$ seems to follow the Log-Normal distribution, i.e.,

$\log _{10}\left(\frac{\tau^{\text {POLDER }}}{\tau^{\mathrm{MODIS}}}\right) \sim N\left(\mu, \sigma^{2}\right)$.

This is probably because both $\tau^{\text {POLDER }}$ and $\tau^{\text {MODIS }}$ follow the Log-Normal distribution. The median value of $\tau^{\text {POLDER }} / \tau^{\text {MODIS }}$ is 0.68 . The black line in Fig. 3 corresponds to $0.68 \tau^{\text {MODIS }}$, which apparently fits POLDER retrievals fairly well. The PDF of $\tau^{\text {POLDER }} / \tau^{\text {MODIS }}$ indicates that for half of total pixels $\tau^{\text {POLDER }}$ is smaller than $\tau^{\text {MODIS }}$ by more than about $30 \%$. The cumulative distribution of $\tau^{\text {POLDER }} / \tau^{\text {MODIS }}$ in Fig. $4 \mathrm{~b}$ at unity is close to $80 \%$. It indicates that $\tau^{\text {POLDER }}$ is smaller than $\tau^{\text {MODIS }}$, (i.e., $\tau^{\text {POLDER }} / \tau^{\text {MODIS }}<1$ ) for about $80 \%$ of the total pixels. The comparison reveals that there exists a substantial bias between MODIS and POLDER operational ice cloud $\tau$ retrievals.

As discussed in Sect. 2, MODIS and POLDER ice $\tau$ retrieval algorithms are different in several respects. Among these differences, the following three may significantly contribute to the bias between $\tau^{\text {POLDER }}$ and $\tau^{\text {MODIS }}$. 1) Difference in retrieval resolution. It is known that the retrieved $\tau$ tends to be smaller than the averaged of the scene due to cloud heterogeneity and the nonlinear dependence of cloud reflection on $\tau$ (Cahalan et al., 1994; Oreopoulos and Davies, 1998). This difference is usually termed as the "plane-parallel albedo bias". As aforementioned, $\tau$ POLDER for each collocated pixel is from the POLDER level-2 product, in which cloud optical thickness is retrieved from cloud reflection measured at the resolution of $18 \times 18 \mathrm{~km}^{2}$, while $\tau^{\text {MODIS }}$ for each collocated pixel is an arithmetic mean of MODIS level-2 retrievals with spatial resolution of $1 \times 1 \mathrm{~km}^{2}$. Therefore, the plane-parallel bias is a potential reason causing $\tau^{\text {POLDER }}$ to be smaller than $\tau^{\text {MODIS }} .2$ ) Difference in cloud effective radius. As aforementioned, MODIS retrieves $r_{e}$, while in POLDER retrieval the $r_{e}$ of all ice clouds is assumed to be $30 \mu \mathrm{m}$. This difference in the treatment of $r_{e}$ may contribute to the bias between $\tau^{\text {POLDER }}$ and $\tau^{\text {MODIS, }}$ although according to the MODIS cloud product ice clouds in Fig. 2 have a mean $r_{e}$ of $28.18 \mu \mathrm{m}$. 3) Difference in ice particle model. As mentioned in the introduction, the ice particle model may significantly affect the retrieval results of the "solar reflective method", so the differences between the Baum05 and IHM model may be an important reason explaining the bias between $\tau^{\text {POLDER }}$ and $\tau^{\text {MODIS }}$.

To identify the relative importance of the above three reasons, the following three experiments are conducted for the granule in Fig. 2. In experiment A, based on the Baum05 model with $r_{e}$ assumed to be $30 \mu \mathrm{m}$, ice cloud $\tau$ is retrieved from the collocated MODIS radiances $\left(6 \times 6 \mathrm{~km}^{2}\right)$. In experiment $\mathrm{B}$, the retrieval is based on the IHM model and the collocated POLDER radiances $\left(6 \times 6 \mathrm{~km}^{2}\right)$. Experiment $\mathrm{C}$ is the same as experiment B, except that it is based on the Baum05 model $\left(r_{e}=30 \mu \mathrm{m}\right)$. The configurations of the three experiments are summarized in the Table 2. A Lambertian surface has been assumed in all experiments. The surface reflectance is determined from the observations in the clear-sky region. Hereafter, the retrievals from these three experiments will be denoted as $\tau^{A}, \tau^{B}$ and $\tau^{C}$, respectively. The PDFs of $\tau^{B} / \tau^{A}$ and $\tau^{C} / \tau^{A}$ are shown in Fig. 4a and the corresponding cumulative distributions are shown in Fig. 4b. The statistics of $\tau^{B} / \tau^{A}$ and $\tau^{C} / \tau^{A}$ are listed in Table 3, together with those of $\tau^{\text {POLDER }} / \tau^{\text {MODIS }}$. Evidently, $\tau^{B} / \tau^{A}$ shares quite similar statistics with $\tau^{\mathrm{POLDER}} / \tau^{\text {MODIS }}$. This similarity indicates that the substantial bias between POLDER and MODIS retrievals remains largely unchanged, even if they are made at the same resolution and treat $r_{e}$ in the same way in their algorithms (see Table 2). However, as indicated by the similarity between $\tau^{C}$ and $\tau^{A}$, the bias between POLDER and MODIS ice $\tau$ retrievals disappears almost completely when the same ice particle model (i.e., the Baum05 model) is used in both retrievals.

The above results clearly show that the bias between MODIS and POLDER ice cloud $\tau$ retrievals is primarily attributable to the use of different ice particle models in their algorithms. But why does POLDER retrieval tend to be smaller? The underlying physics is as follows: It has been shown that the observed cloud reflectivity at a non-absorbing wavelength, such as the $0.86 \mu \mathrm{m}$, is generally proportional 
Table 2. Configurations of three experiments.

\begin{tabular}{clll}
\hline Experiment & $\begin{array}{l}\text { Radiance } \\
\text { source }\end{array}$ & $\begin{array}{l}\text { Radiance } \\
\text { resolution }\end{array}$ & $\begin{array}{l}\text { Bulk scattering } \\
\text { model }\end{array}$ \\
\hline A & MODIS & $6 \times 6 \mathrm{~km}^{2}$ & Baum05 $\left(r_{e}=30 \mu m\right)$ \\
B & POLDER & $6 \times 6 \mathrm{~km}^{2}$ & $\operatorname{IHM~}\left(r_{e}=30 \mu m\right)$ \\
$\mathrm{C}$ & POLDER & $6 \times 6 \mathrm{~km}^{2}$ & Baum05 $\left(r_{e}=30 \mu \mathrm{m}\right)$ \\
\hline
\end{tabular}

Table 3. Statistics of the ratios, $\tau^{\text {POLDER }} / \tau^{\text {MODIS }}, \tau^{B} / \tau^{A}$ and $\tau^{C} / \tau^{A}$

\begin{tabular}{llllll}
\hline Comparison & Distribution & Mean & Median & Std & $\mathrm{C}(1.0)^{*}$ \\
\hline$\tau^{\text {POLDER }}$ & Log-Normal & 0.8082 & 0.6811 & 0.9483 & $80.53 \%$ \\
$\tau^{\text {MODIS }}$ & & & & & \\
$\tau^{B} / \tau^{A}$ & Log-Normal & 0.7703 & 0.6879 & 0.3802 & $86.38 \%$ \\
$\tau^{C} / \tau^{A}$ & Normal & 1.0880 & 0.9851 & 0.5109 & $52.53 \%$ \\
\hline
\end{tabular}

* $\mathrm{C}(1.0)$ corresponds to the value of cumulative distribution at unity.

to the scaled optical thickness, $(1-g) \tau$, (van de Hulst, 1980; King, 1987). In other words, the retrieved $\tau$ is proportional to $1 /(1-g)$. Therefore, since the IHM model has a smaller $g$ than the Baum05 model, an ice cloud is more reflective if it consists of IHM particles than Baum05 particles. In other words, from the perspective of retrieval, smaller (larger) $\tau$ will be retrieved from the same observation if the IHM (Baum05) model is assumed in the algorithm.

\section{Climate implications}

\subsection{Implications for the calculation of cloud radiative forcing of ice clouds from satellite observations}

Presently, satellite data are widely used in climate studies, for example to derive cloud and aerosol climatologies and compare with GCM simulations. However, satellite data must account for various uncertainties. For example, as indicated by the substantial difference between MODIS and POLDER retrievals, there may exist considerable uncertainties in satellite retrievals of ice cloud optical thickness. In this section, we address the question: How, and to what extent, does the uncertainty in satellite retrievals affect our understanding of the radiative effects of ice clouds?

An important parameter to measure cloud radiative effects is the cloud radiative forcing (CRF), which consists of two parts, the shortwave and longwave CRF. In this study we focus only on the shortwave CRF of ice clouds for a number of reasons, but primarily because both MODIS and POLDER retrieve cloud optical thickness using shortwave bands. Fol-

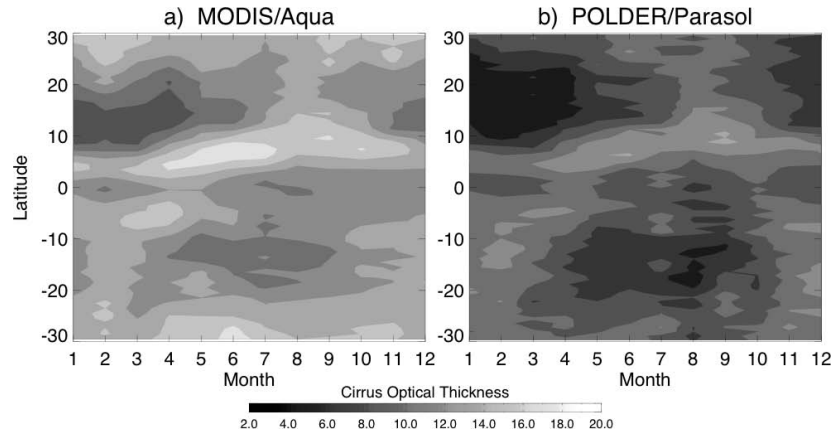

Fig. 5. Zonally-averaged monthly mean ice cloud optical thickness as function of latitude and month derived from (a) MODIS and (b) POLDER cloud products.

lowing Ramanathan, et al. (1989), the shortwave CRF of ice clouds, denoted as $\left(F_{S W}\right)$ hereafter, is defined as:

$F_{S W}=\left(F_{S W}^{\text {cloudy }}-F_{S W}^{\text {clear }}\right) f_{\text {ice }}$,

where $F_{S W}^{\text {cloudy }}$ and $F_{S W}^{\text {clear }}$ denote the net downward flux of shortwave radiation at the top of atmosphere (TOA) with and without the presence of ice clouds, respectively. The $f_{\text {ice }}$ is the ice cloud fraction.

One way to derive CRF is to compute it from satelliteretrieved cloud properties using radiative transfer models. Figure 5a shows zonally-averaged Aqua MODIS level-3 monthly mean (i.e., MODIS product "MYD08_M3") ice cloud optical thickness in the tropics as a function of latitude and month for the year 2007. Figure 5b shows the corresponding POLDER observations (i.e., POLDER product "RB3"). An important point to bear in mind is that both MODIS and POLDER are on board of polar-orbiting satellites and therefore their level-3 products are the average of "snapshots", rather than continuous observations. The two data sets agree largely on overall patterns. However, as expected, POLDER observations are substantially smaller than those from MODIS. Based on the MODIS observation in Fig. 5a and the Baum05 model, we compute the $F_{S W}^{\mathrm{MODIS}}$ using a radiation model developed by Chou et al. (1992). Note that a new broadband parameterization scheme has been developed based on the Baum05 model to replace the original one in Chou's code for the $F_{S W}^{\mathrm{MODIS}}$ computation. Similarly, we compute the $F_{S W}^{\mathrm{POLDER}}$ based on the POLDER observations and an extended IHM model that includes the scattering properties over the entire solar spectral region. For the purpose of comparison, another set of CRF, $F_{S W}^{P B}$, is computed based on POLDER retrievals using the Baum05 model. In all computations, ice cloud effective radius is assumed as $30 \mu \mathrm{m}$. The ice clouds are placed in a layer between 175 and $225 \mathrm{hPa}$ of a tropical atmosphere. It is important to point out that the diurnal cycle and sunlight duration are not considered in these computations. Instead, the monthly mean solar zenith angle from MODIS level-3 product is used. Thus, 


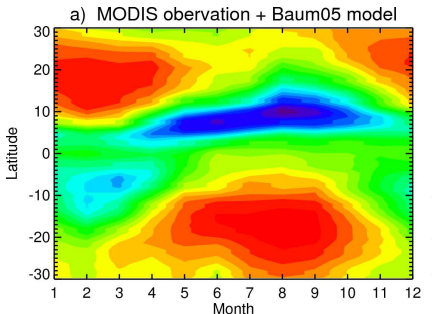

b) POLDER obervation + IHM model
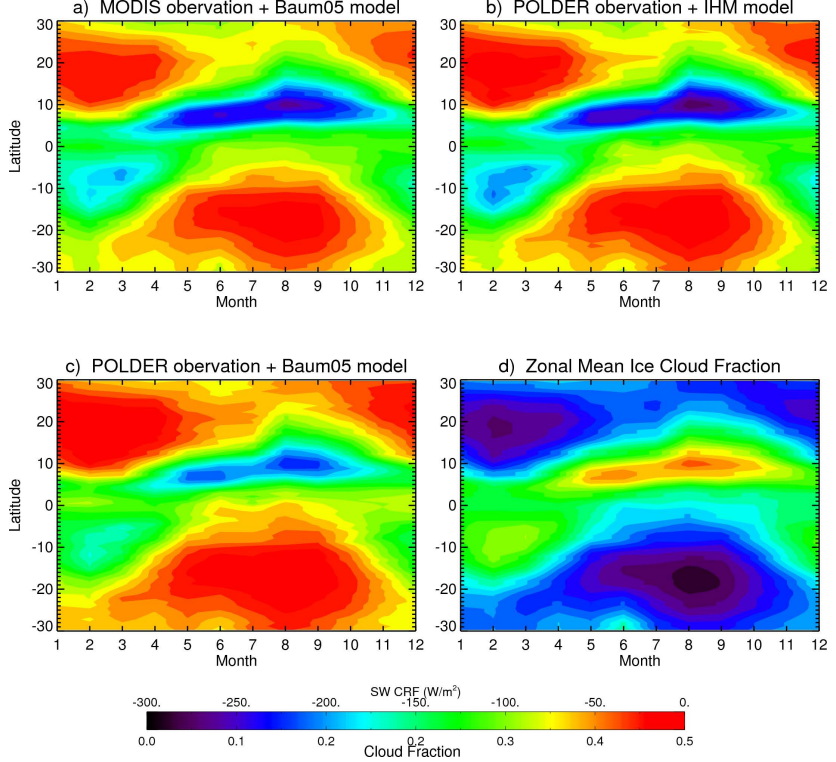

Fig. 6. Three sets of ice cloud shortwave CRF. (a) is derived from MODIS ice cloud $\tau$ retrieval in Fig. 5a using the Baum05 model to specify the radiative properties of ice particles. (b) from POLDER retrieval in Fig. 5b using the IHM model. (c) same as (b) except that the Baum05 model is used. (d) zonal mean ice cloud fraction from MODIS level-3 data.

$F_{S W}^{\mathrm{MODIS}}, F_{S W}^{\mathrm{POLDER}}$ and $F_{S W}^{P B}$, shown in Fig. 6, are instantaneous, rather than daily-averaged, $\mathrm{CRF}$, because of this configuration and the above-mentioned nature of MODIS and POLDER level-3 products. For many reasons, MODIS and POLDER may retrieve different ice cloud fractions. However, in order to focus on the effect of ice particle model on $F^{S W}$, the same zonal mean the ice cloud fraction $f_{i c e}$ from MODIS level-3 data (see Fig. 6d) is used in all computations.

Inspection of Fig. 6 immediately reveals that $F_{S W}^{\mathrm{MODIS}}$ and $F_{S W}^{\mathrm{POLDER}}$ agree relatively well, while $F_{S W}^{P B}$ is substantially weaker (less negative). Given the substantial difference between MODIS and POLDER retrievals, the relatively good agreement between $F_{S W}^{\mathrm{MODIS}}$ and $F_{S W}^{\mathrm{POLDER}}$ might appear somewhat surprising. However, the conversion of observed reflectance to optical thickness and subsequently to cloud albedo does not have a strong dependence on the assumed microphysical model as long as a consistent model is used in both steps. From a given observed reflectance, we can derive two very different optical thicknesses by using two different microphysical ice models but still end up with two fairly close values of cloud albedo if the microphysical model is kept consistent in both steps. And of course, similar albedos would in turn lead to relatively good agreement in the derived shortwave fluxes. This merely reemphasizes the importance of the scaled optical thickness $(1-g) \tau$, discussed at the end of Sect. 3.2. A single wavelength reflectance measurement, such as POLDER, can only explicitly retrieve the scaled optical thickness; a transformation to absolute optical thickness requires an assumption about the phase function (i.e., microphysics, which MODIS simultaneously retrieved though also subject to ice model assumptions). Further, for the present discussion, scaled optical thickness is the relevant radiative quantity for flux calculations. In summary, this comparison illustrates that the uncertainty associated with the ice particle model impacts our understanding of the CRF of ice clouds much less than it does on satellite $\tau$ retrievals. This is the reason for the relatively good agreement between $F_{S W}^{\mathrm{MODIS}}$ and $F_{S W}^{\mathrm{POLDER}}$. More specifically we can describe the mechanism as follows. It is shown that the strength of shortwave CRF increases with $\tau$ but decreases with increasing $g$ (Fu and Liou, 1993). Therefore, although $\tau^{\text {POLDER }}$ is substantially smaller than $\tau^{\text {MODIS }}$, in radiative transfer computations this difference is largely canceled by the difference between the IHM and Baum05 model in $g$, which leads to similar estimates of CRF. This reason also explains why $F_{S W}^{P B}$ is substantially weaker than both $F_{S W}^{\mathrm{MODIS}}$ and $F_{S W}^{\mathrm{POLDER}}$. The combination of smaller $\tau$ retrieval (i.e., $\tau^{\text {POLDER }}$ ) and larger $g$ (i.e., that of the Baum05 model) eliminates the necessary condition for the above cancellation mechanism and therefore makes $F_{S W}^{P B}$ substantially weaker. The above comparison again illustrates clearly the well-established importance to use the same ice particle model in both retrieval and CRF computations. In recognition of this importance, the MODIS team is planning to include the ice particle scattering properties associated with the size retrievals as part of the Collection 6 operational product (S. Platnick, personal communication, 2009).

Nevertheless, it needs to be stressed that the difference between $F_{S W}^{\mathrm{MODIS}}$ and $F_{S W}^{\mathrm{POLDER}}$ is still noticeable. The former is stronger for optically thin ice clouds, while the latter is stronger for optically thick ice clouds. The difference between $F_{S W}^{\mathrm{MODIS}}$ and $F_{S W}^{\mathrm{POLDER}}$ makes it clear that different understandings of ice particle microphysics may lead not only to different ice cloud $\tau$ retrievals but also to different estimates of the radiative effects of ice clouds. Therefore, further efforts are needed to improve our understanding of the microphysical and optical properties of ice clouds.

\subsection{Potential implications for the derivation of seasonal variation of ice optical thickness from satellite mea- surements}

The importance of $g$ in the ice optical thickness retrieval and calculation of ice radiative forcing has been demonstrated in the comparison of MODIS and POLDER ice retrievals in section 1.2, as well as in many previous studies (e.g., Stephens et al., 1990; Liou and Takano, 1994; Macke et al., 1996a; Mishchenko et al., 1996; Schlimme et al., 2005; Fu, 2007). However, only recently has the influence of the pattern of $P_{11}$ on ice optical thickness retrieval been discussed (e.g., Doutriaux-Boucher et al., 2000; C.-Labonnote et al., 2001; Knap et al., 2005; Baran and Labonnote, 2006). These studies indicate that optical thickness retrievals that are based 


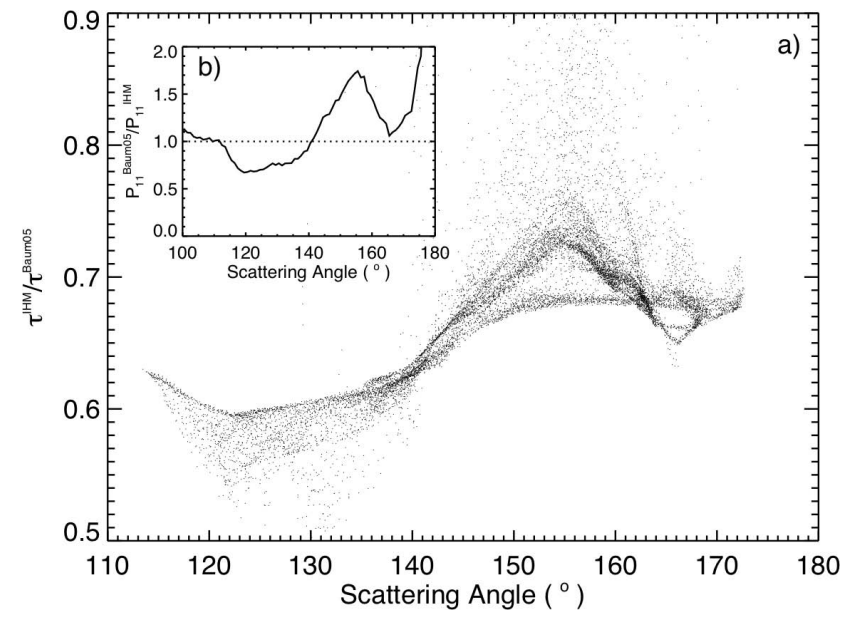

Fig. 7. The ratio of (a) $\tau_{c}^{\mathrm{IHM}} / \tau_{c}^{\mathrm{Baum} 05}$ and (b) $P_{11}^{\mathrm{Baum} 05} / P_{11}^{\mathrm{IHM}}$ as a function of scattering angle.

on different ice scattering phase functions can differ substantially. More importantly, these studies found that the magnitude of the difference is dependent on the scattering angle $\left(\theta_{s}\right)$ specified by the sun-satellite viewing geometry as follows:

$\cos \theta_{s}=\cos \left(\pi-\theta_{0}\right) \cos \theta_{v}+\sin \theta_{0} \sin \theta_{v} \cos \left(\phi_{v}-\phi_{0}\right)$,

where the definitions of $\theta_{0}, \theta_{v}, \phi_{0}, \phi_{v}$ are the same as those in Eq. (1). To illustrate the above point, two sets of ice optical thickness retrievals are performed for the granule in Fig. 2 from MODIS observations. The Baum05 model is used in one retrieval, the IHM model in the other. Hereafter, the two retrievals will be referred to as $\tau^{\mathrm{Baum} 05}$ and $\tau^{\mathrm{IHM}}$, respectively. Figure 7a shows $\tau^{\mathrm{IHM}} / \tau^{\text {Baum05 }}$ as a function of $\theta_{s}$. Note that each point in Fig. 7a corresponds to an ice cloud pixel in the granule. Two features in Fig. 7a are quite intriguing. First of all, the ratio is substantially smaller than unity, which may be attributed to the difference in asymmetry factor between the IHM and Baum05 models. Secondly, and more importantly here, it is evident that the difference between $\tau^{\mathrm{IHM}}$ and $\tau^{\mathrm{Baum} 05}$ is a strong function of $\theta_{s}$. For example, the ratio increases about $10 \%$ as $\theta_{s}$ increases from about $120^{\circ}$ to $140^{\circ}$.

One may notice that the angular pattern of $\tau^{\mathrm{IHM}} / \tau^{\text {Baum05 }}$ in Fig. 7a closely resembles that of $P_{11}^{\text {Baum05 }} / P_{11}^{\mathrm{IHM}}$ in Fig. $7 \mathrm{~b}$. Several previous studies have also noticed such a resemblance (e.g., Doutriaux-Boucher et al., 2000; C.-Labonnote et al., 2001; Knap et al., 2005; Baran and Labonnote, 2006). However, the reason behind this resemblance still remains unexplained. We suggest that the resemblance can be explained by the physics schematically shown in Fig. 8. Because of the diffraction, the shortwave scattering phase function of ice particles usually has a strong peak in the forward direction, i.e., $\theta_{s}=0^{0}$ (Macke et al., 1995; Yang and Liou, 1996). As a consequence, the possibility of a photon be-

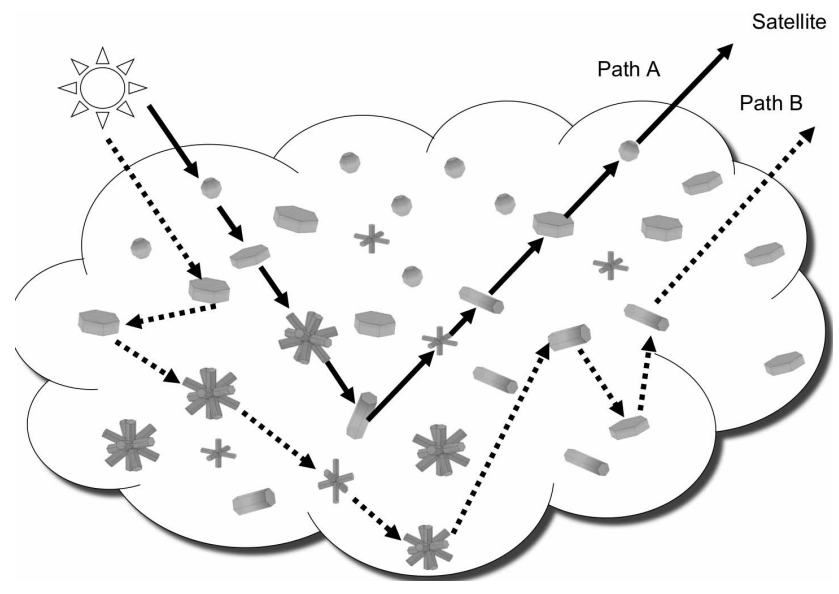

Fig. 8. Schematic illustration of two possible paths of photons within ice cloud. Note that back scattering event occurs only once in "Path A", but several times in "Path B".

ing scattered in the forward direction by an ice particle is much larger than that of being scattered in the side or back directions, i.e., $\theta_{s}>90^{\circ}$. An implication of this is that, within thin ice clouds, the occurrence probability of photons following the "Path A" in Fig. 8 is much larger than that of other paths, such as the "Path B" in Fig. 8. In "Path A" backscattering occurs only one time, while multiple side-scattering or backscattering events will occur if a photon travels along any other path. As clouds increase in optical thickness, the contributions to cloud reflectance from photons following the "Path B" will increase. However, there is still a considerable number of photons that follow "Path A". Because these photons going through the "Path A" carry the information of $P_{11}$, the bi-directional reflectances and therefore the retrieved optical thickness of ice clouds are correlated to the $P_{11}$ of the ice particles.

In the remainder of this section, we will elucidate a potential implication of this $\theta_{s}$-dependent difference between $\tau^{\text {Baum05 }}$ and $\tau^{\mathrm{IHM}}$ in deriving the seasonal variations of ice cloud optical thickness from observations of instruments like MODIS and VIIRS. These instruments perform nadirviewing, cross-track scanning for data sampling (Salomonson et al., 1989; Miller et al., 2006). This scanning pattern is independent of season. As a result, the seasonal cycle of the sun-satellite viewing geometry and the corresponding $\theta_{s}$ are largely determined by the position of the sun. As schematically illustrated in Fig. 9a, $\theta_{s}$ increases as solar zenith angle $\left(\theta_{0}\right)$ decreases from winter to summer and then decreases as the sun returns to its winter position. This seasonal dependence of MODIS $\theta_{s}$ is clearly seen in Fig. 9b which shows the map of zonal and monthly mean MODIS $\theta_{s}$, derived from MODIS level-3 product, as a function of latitude and month.

The seasonal dependence of MODIS $\theta_{s}$ and the aforementioned dependence of $\tau^{\mathrm{IHM}} / \tau^{\mathrm{Baum} 05}$ on $\theta_{s}$ together have an intriguing implication. That is, the difference between 

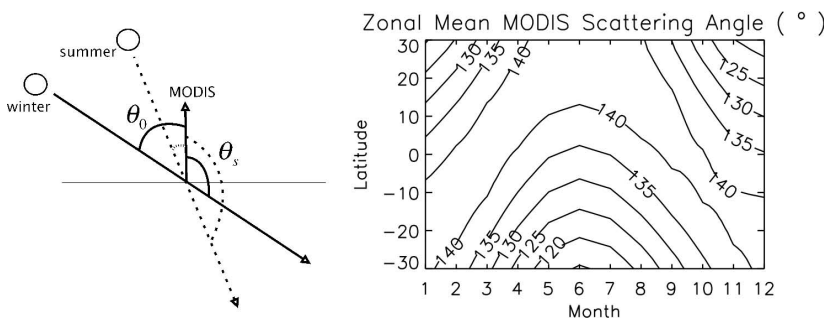

Fig. 9. (a) Schematic illustration of the seasonal dependence of solar zenith angle $\theta_{0}$ and MODIS scattering angle $\theta_{s}$. (b) Zonal mean $\theta_{S}$ as functions of latitude and month.

$\tau^{\mathrm{IHM}}$ and $\tau^{\mathrm{Baum} 05}$ tends to be statistically smaller (the ratio $\tau^{\mathrm{IHM}} / \tau^{\text {Baum05 }}$ is closer to unity) in summer than in winter. This indicates that the use of different ice particles models or, more specifically, different scattering phase functions may lead to different results for the seasonal variation of ice cloud optical thickness.

This implication is further illustrated in the following theoretical example. In this example, we consider a MODIS granule at the latitude of $15^{\circ} \mathrm{N}$. We assume that this granule is overcast by ice clouds with the same optical thickness and effective radius. We further assume that the scattering properties of these ice clouds follow the IHM model. In other words, if the MODIS retrieval algorithm were based on the IHM model, the retrieved optical thickness would be close to the assumed value, i.e., $\tau^{\mathrm{IHM}}$. We then retrieve $\tau^{\text {Baum05 }}$ for this granule at different months of the year based on the Baum05 model. The monthly mean solar zenith and azimuthal angles from MODIS level 3 data are used to specify the position of the sun in the retrieval. The MODIS viewing geometry is assumed to be independent of season and specified using the sensor zenith and azimuthal angles from level 1 data. The relative differences between the retrieved $\tau^{\text {Baum05 }}$ (averaged over the granule) and the assumed $\tau^{\mathrm{IHM}}$ at different values of $\tau^{\mathrm{IHM}}$ are shown in Fig. 10 as a function of month. It is interesting to note that the difference between $\tau^{\text {Baum05 }}$ and $\tau^{\mathrm{IHM}}$ can be divided into two parts. To the first order, $\tau^{\text {Baum05 }}$ is substantially larger than $\tau^{\mathrm{IHM}}$. As discussed earlier, this is caused by the difference in asymmetry factor between the IHM and Baum05 model. Secondly, and more importantly in this context, the difference shows a significant seasonal pattern. $\tau^{\text {Baum05 }}$ retrieval is larger in winter than summer. This second-order difference is observed in all cases and can be quite considerable when the cloud is optically thin. The above example illustrates a potential uncertainty in deriving ice cloud optical thickness from satellite instruments like MODIS and the future VIIRS imager on NPOESS platforms. That is, the use of different ice bulk scattering models may lead to different understandings of the seasonal variation of ice cloud optical thickness. To our knowledge, this uncertainty has not been discussed before in the literature, but reinforces the importance of improving

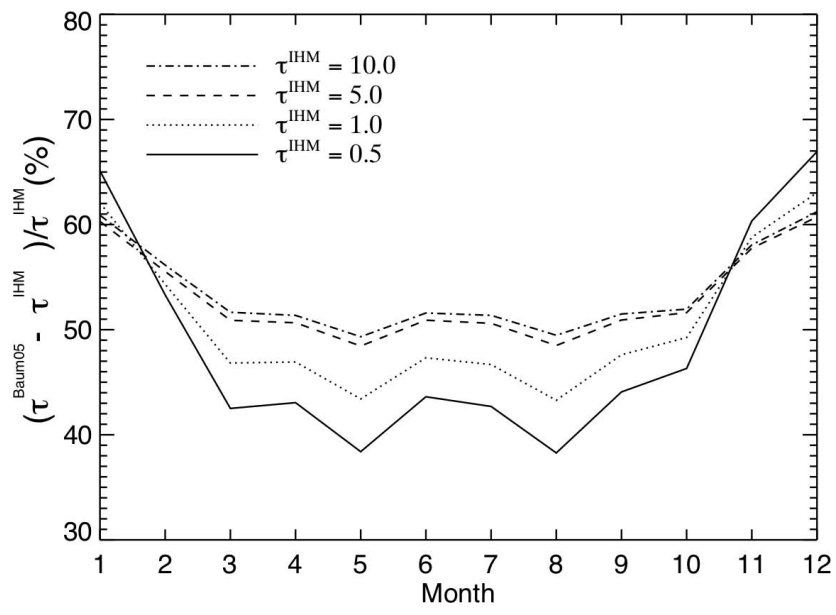

Fig. 10. Relative difference between the assumed $\tau^{\mathrm{IHM}}$ and the $\tau^{\text {Baum05 }}$ retrieved based on the Baum05 model as a function of month of the year.

our understanding of the microphysics of ice particles for satellite remote sensing applications. Further study is warranted to better understand uncertainties in satellite-based retrievals and in subsequent studies of the climatic importance of global ice cloud properties.

A final consideration from these results is that observing instruments with multi-angle viewing capability such as POLDER, MISR (Multiangle Imaging SpectroRadiometer) or AATSR (Advance Along Track Scanning Radiometer) will be less affected by this source of uncertainty since they tend to provide a more extensive and homogeneous sampling of scattering angle and thus phase function over all seasons. Future studies could investigate if a combination of POLDER and MODIS observations can help reduce the uncertainties in the seasonal cycle determination of ice cloud properties.

\section{Summary and discussion}

In this paper, we have been mainly concerned with the influences of two very different ice particle microphysical and optical models on the resulting optical thickness retrievals from satellite measurements of solar reflection. We assessed the influences by comparing the retrievals based on two different ice particle models, the Baum05 and the IHM model. We also studied the implications of the comparisons for climate studies. Our main findings are: 1) The ice cloud optical thickness retrieval from POLDER is substantially smaller than that from MODIS. This difference may be attributed primarily to the difference of asymmetry factor between the Baum05 and the IHM models. 2) Different assumptions of the ice particle models may lead not only to different optical thickness retrievals but also to significantly different estimates of the shortwave CRF of ice clouds. 3) In CRF computations the difference in ice cloud optical thickness retrievals 
tends to be offset by the difference in optical properties (such as the asymmetry factor) of ice clouds. 4) The use of different ice cloud bulk scattering models may lead to different results for the seasonal variation of ice cloud optical thickness. In summary, the above findings indicate that ice cloud optical thickness retrievals based on satellite measurements of solar reflection are highly sensitive to the choice of the ice particle model assumed in the retrieval. This sensitivity makes our inadequate knowledge of the microphysics of ice particles the main source of uncertainty in optical thickness retrievals, at least for those retrieval algorithms based on solar reflection observations. Therefore, to improve our understanding of the role of ice clouds in the climate, we must continue to improve our understanding of the microphysical and optical properties of ice particles.

The above findings suggest that the lack of a common base to interpret satellite measurements is a great obstacle for establishing a long-term climatology of ice cloud properties from multiple satellite missions. Many satellite instruments, such as the AVHRR, MODIS, POLDER and the future VIIRS and GOES-R sensors, retrieve ice cloud optical thickness from the measurements of their solar-reflective bands. We note that at the time of this writing, the PATMOS-x climatology (based on AVHRR; (Heidinger et al., 2005)) and MODIS use the Baum05 models. However, a common set of models has not been defined or advocated for use by every sensor. Because the ice particle models used in operational retrievals are usually different from one another, a direct combination of the resulting products into a climatology would be almost meaningless. We therefore suggest that a set of existing or newly developed ice particle models should be used as the common basis to derive a climatology of ice cloud optical thickness from satellite measurements. A goal is to provide a consistent way to interpret satellite-based decadal measurements, so that comparable retrievals can be derived from different satellite missions and a long-term record of ice cloud optical thickness can be established for climate studies.

The above point raises an important question: Which model is more appropriate in terms of representing the nature of ice clouds, the Baum05 or the IHM model, or some other models in the existing literature? Although we do not have the ambition in this paper to answer this question, we shall outline our understanding of the advantages and limitations of the Baum05 and the IHM models and hope that the analysis may help in the development of future ice particle models. A number of reasons contribute to the dramatic differences between the Baum05 and the IHM models. Perhaps the most important one is that the instrument differences between MODIS and POLDER lead to different ice cloud retrieval methods, which in turn lead to different perspectives on the appropriateness of ice particle models. This point should be kept in mind when understanding the strengths and limitations of the two models. The strengths of the Baum05 model stem from its root in the in-situ measurements of ice clouds. The theoretically derived ice wa- ter content and median mass diameter based on the Baum05 mode agrees closely with the in-situ measurements. More than 1000 ice particle size distributions are used to derive not only the mean values, but also the variability of ice cloud parameters (Baum et al., 2005). The former is used to retrieve the expected cloud optical thickness and effective radius; the latter is needed for the assessment of retrieval uncertainty. The Baum05 model also provides a connection between ice particle optical properties with the measured environmental conditions, such as the temperature and humidity, which are the key variants in the ice cloud parameterization schemes for GCMs (Donner et al., 1997; Kristjánsson et al., 2000). A very attractive advantage of the IHM model has been demonstrated in many studies (C.-Labonnote et al., 2000; Doutriaux-Boucher et al., 2000; C.-Labonnote et al., 2001; Baran and Labonnote, 2006). These studies showed that based on the IHM model consistent ice cloud spherical albedos are retrieved from POLDER observations at different viewing directions, while use of a scattering phase function based on pristine and smooth ice hexagonal columns or plates such as those used in Baum05 model may lead to inconsistent retrievals. Some other studies (Foot, 1988; Francis, 1995; Francis et al., 1999; Baran et al., 2001; Field et al., 2003; Jourdan et al., 2003) based on airborne measurements of ice particle scattering properties also found that the smooth and featureless scattering phase function similar to that of the IHM model yields best agreements with measurements. In addition to the inclusion of air bubbles, the increase of ice particle complexity (Macke et al., 1995) and surface roughness (Hess et al., 1998; Yang et al., 2008) may also effectively reduce or even smooth out the features, such as the halos, in phase functions. Work is underway to modify the Baum05 model to include the scattering properties of ice particles with medium and deeply roughened surfaces. (B. Baum, personal communication, 2008). Despite the above evidence indicating the predominance highly randomized particles (i.e., ice particle with air bubbles or deeply roughened surfaces) in ice clouds, halos are frequently observed, and a recent study by Sherwood (2005), indicates the existence of a considerable number of pristine and smooth ice crystals that probably have phase functions similar to that of Baum05 model. The frequency of occurrence of these ice particles, especially on the global scale, is still an open question for further investigation.

Finally, the above analysis suggests that to delineate a comprehensive picture of ice clouds requires the synergetic use of instruments with different, yet complementary capabilities. The A-train mission has provided an excellent opportunity for such tasks. The combination of MODIS and POLDER or MISR observations would capture both the spectral and directional variability of cloud reflectance. The polarization observations from POLDER and the future APS (Aerosol Polarimetry Sensor) (Mishchenko et al., 2007) may help to differentiate the ice particle models that have similar scattering phase functions but different 
polarization signatures (Baran and Labonnote, 2006). The integrated cloud lidar and radar observations have been used to map the vertical distribution of clouds (Sassen et al., 2008). They also provide the information about the cloud or aerosol layers under ice clouds, which will help to reduce the uncertainty associated with multiple cloud layer conditions in passive remote sensing of ice clouds. The MLS (Microwave Limb Sounder) on board Aura is ideal for remote sensing of ice cloud at high altitude (Wu et al., 2006). The infrared observations from MODIS and AIRS have been demonstrated to be useful for inferring ice cloud properties (e.g., Wei et al., 2004; Cooper et al., 2006; L' Ecuyer et al., 2006; Wendisch et al., 2007; Yue et al., 2007). A combination of observations in both solar and infrared region can help to differentiate ice particle models that have similar scattering properties in solar spectral region but different absorption characteristics in the infrared region (Baran and Francis, 2004). The AIRS temperature and humidity profile products connect the observed ice clouds with the environmental conditions (Kahn et al., 2008). This helps to reveal the mechanisms of ice cloud formation and maintenance and is useful for the development and evaluation of ice cloud parameterization schemes in GCMs (Donner et al., 1997; Kristjánsson et al., 2000). In summary, the synergies of A-train sensors have the potential to make progress on some of the most challenging issues and help in the development of a comprehensive ice particle model for deriving long-term ice cloud climatology from different satellite missions.

Acknowledgements. The authors are very grateful to CNES and NASA for providing the POLDER/PARASOL and MODIS/AQUA data used in this study. We thank the ICARE Data and Services Center for providing access to the data and for general assistance and development support. The authors wish to thank F. Thieuleux (USTL/CNRS) for his help in development of POLDER/MODIS merging software. This study was supported by NASA (NNG04GL24G and NNX08AF68G) and partly by the National Science Foundation (ATM-0239605). Bryan Baum's research is supported by NASA grants NNX08AF81G and NNX08AF78A. George Kattawar's research is supported by the Office of Naval Research under the contract N00014-06-1-0069.

Edited by: S. Buehler

\section{References}

Baran, A. J., Watts, P. D., and Francis, P. N.: Testing the coherence of cirrus microphysical and bulk properties retreived from dualviewing multispectral satellite radiance measurements, J. Geophys. Res., 104, 31673-31683, 1999.

Baran, A. J., Francis, P. N., Labonnote, L. C., and DoutriauxBoucher, M.: A scattering phase function for ice cloud: Tests of applicability using aircraft and satellite multi-angle multiwavelength radiance measurements of cirrus, Q. J. Roy. Meteor. Soc., 127, 2395-2416, 2001.

Baran, A. J. and Francis, P. N.: On the radiative properties of cirrus cloud at solar and thermal wavelengths: A test of model consis- tency using high-resolution airborne radiance measurements, Q. J. Roy. Meteor. Soc., 130, 763-778, 2004.

Baran, A. J. and Labonnote, L. C.: On the reflection and polarisation properties of ice cloud, JQSRT, 100, 41-54, 2006.

Baran, A. J. and Labonnote, L. C.: A self-consistent scattering model for cirrus. I: The solar region, Q. J. Roy. Meteor. Soc., 133, 1899-1912, 2007.

Baum, B., Yang, P., Heymsfield, A., and Thomas, S.: Bulk Scattering Properties for the Remote Sensing of Ice Clouds. Part I: Microphysical Data and Models, Journal of Appl. Meteor., 44, 1885-1895, 2005.

Bony, S., Colman, R., Kattsov, V. M., Allan, R. P., Bretherton, C. S., Dufresne, J.-L., Hall, A., Hallegatte, S., Holland, M. M., Ingram, W., Randall, D. A., Soden, B. J., Tselioudis, G., and Webb, M. J.: How Well Do We Understand and Evaluate Climate Change Feedback Processes?, J. Climate, 19, 3445-3482, 2006.

Buriez, J. C., Parol, F., Cornet, C., and Doutriaux-Boucher, M.: An improved derivation of the top-of-atmosphere albedo from POLDER/ADEOS-2: Narrowband albedos, J. Geophys. Res., 110, D05202, doi:05210.01029/02004JD005243., 2005.

C.-Labonnote, L., Brogniez, G., Doutriaux-Boucher, M., Buriez, J. C., Gayet, J. F., and Chepfer, H.: Modeling of light scattering in cirrus clouds with inhomogeneous hexagonal monocrystals. Comparison with in-situ and ADEOS-POLDER measurements, Geophys. Res. Lett., 27, 113-116, 2000.

C.-Labonnote, L., Brogniez, G., Buriez, J. C., Doutriaux-Boucher, M., Gayet, J. F., and Macke, A.: Polarized light scattering by inhomogeneous hexagonal monocrystals: Validation with ADEOS-POLDER measurements, J. Geophys. Res., 106, 12139-12155, 2001.

Cahalan, R. F., Ridgway, W., Wiscombe, W. J., Bell, T. L., and Snider, J. B.: The Albedo of Fractal Stratocumulus Clouds, J. Atmos. Sci., 51, 2434-2455, 1994.

Chou, M. D.: A Solar Radiation Model for Use in Climate Studies, J. Atmos. Sci., 49, 762-772, 1992.

Comstock, J. M., d'Entremont, R., DeSlover, D., Mace, G. G., Matrosov, S. Y., McFarlane, S. A., Minnis, P., Mitchell, D., Sassen, K., and Shupe, M. D.: An Intercomparison of Microphysical Retrieval Algorithms for Upper-Tropospheric Ice Clouds, Bull. Amer. Meteor. Soc., 88, 191-204, 2007.

Cooper, S. J., Ecuyer, T. S., Gabriel, P., Baran, A. J., and Stephens, G. L.: Objective Assessment of the Information Content of Visible and Infrared Radiance Measurements for Cloud Microphysical Property Retrievals over the Global Oceans. Part II: Ice Clouds, J. Appl. Meteorol. Climatol., 45, 42-62, 2006.

Cox, S. K., McDougal, D. S., Randall, D. A., and Schiffer, R. A.: FIRE-The First ISCCP Regional Experiment, B. Am. Meteor. Soc., 68, 114-118, 1987.

Donner, L. J., Seman, C. J., Soden, B. J., Hemler, R. S., Warren, J. C., Ström, J., and Liou, K.-N.: Large-scale ice clouds in the GFDL SKYHI general circulation model, J. Geophys. Res., 102, 21745-21768, 1997.

Doutriaux-Boucher, M., Buriez, J. C., Brogniez, G., C-Labonnote, L., and Baran, A. J.: Sensitivity of retrieved POLDER directional cloud optical thickness to various ice particle models, Geophys. Res. Lett., 27, 109-112, 2000.

Field, P. R., Baran, A. J., Kaye, P. H., Hirst, E., and Greenaway, R.: A test of cirrus ice crystal scattering phase functions, Geophys. Res. Lett., 30, 1752, doi:10.1029/2003GL017482, 2003. 
Foot, J. S.: Some observations of the optical properties of clouds. II: Cirrus, Q. J. Roy. Meteor. Soc., 114, 145-164, 1988.

Francis, P. N.: Some Aircraft Observations of the Scattering Properties of Ice Crystals, J. Atmos. Sci., 52, 1142-1154, 1995.

Francis, P. N., Foot, J. S., and Baran, A. J.: Aircraft measurements of the solar and infrared radiative properties of cirrus and their dependece on ice crystal shape, J. Geophys. Res., 104, 3168531695, 1999.

Fu, Q., and Liou, K. N.: Parameterization of the Radiative Properties of Cirrus Clouds, J. Atmos. Sci., 50, 2008-2025, 1993.

$\mathrm{Fu}, \mathrm{Q}$.: An Accurate Parameterization of the Solar Radiative Properties of Cirrus Clouds for Climate Models, J. Climate, 9, 20582082, 1996.

Fu, Q., Yang, P., and Sun, W. B.: An Accurate Parameterization of the Infrared Radiative Properties of Cirrus Clouds for Climate Models, J. Climate, 11, 2223-2237, 1998.

Fu, Q.: A New Parameterization of an Asymmetry Factor of Cirrus Clouds for Climate Models, J. Atmos. Sci., 64, 4140-4150, 2007.

Gallagher, M. W., Connolly, P. J., Whiteway, J., Figueras-Nieto, D., Flynn, M., Choularton, T. W., Bower, K. N., Cook, C., Busen, R., and Hacker, J.: An overview of the microphysical structure of cirrus clouds observed during EMERALD-1, Q. J. Roy. Meteor. Soc., 131, 1143-1169, 2005.

Heidinger, A. K., Goldberg, M. D., Tarpley, D., Jelenak, A., and Pavolonis, M. J.: A new AVHRR cloud climatology, Proc. SPIE, 5658, 197, 2005.

Hess, M., Koelemeijer, R. B. A., and Stammes, P.: Scattering matrices of imperfect hexagonal ice crystals, JQSRT, 60, 301-308, 1998.

Heymsfield, A. J., Bansemer, A., Field, P. R., Durden, S. L., Stith, J. L., Dye, J. E., Hall, W., and Grainger, C. A.: Observations and Parameterizations of Particle Size Distributions in Deep Tropical Cirrus and Stratiform Precipitating Clouds: Results from In Situ Observations in TRMM Field Campaigns, J. Atmos. Sci., 59, 3457-3491, 2002.

Heymsfield, A. J.: Properties of Tropical and Midlatitude Ice Cloud Particle Ensembles. Part I: Median Mass Diameters and Terminal Velocities, J. Atmos. Sci., 60, 2573-2591, 2003.

Jensen, E., Starr, D., and Toon, O. B.: Mission investigates tropical cirrus clouds, EOS, 85, 45-50, 2004.

Jensen, E. J., Kinne, S., and Toon, O. B.: Tropical cirrus cloud radiative forcing- Sensitivity studies, Geophys. Res. Lett., 21, 2023-2026, 1994.

Jourdan, O., Oshchepkov, S., Shcherbakov, V., Gayet, J. F., and Isaka, H.: Assessment of cloud optical parameters in the solar region: retrievals from airborne measurements of scattering phase functions, J. Geophys. Res.-Atmos., 108, 4572, doi:10.1029/2003JD003493, 2003.

Kahn, B. H., Liang, C. K., Eldering, A., Gettelman, A., Yue, Q., and Liou, K. N.: Tropical thin cirrus and relative humidity observed by the Atmospheric Infrared Sounder, Atmos. Chem. Phys., 8, 1501-1518, 2008, http://www.atmos-chem-phys.net/8/1501/2008/.

Karlsson, K. G.: A 10 year cloud climatology over Scandinavia derived from NOAA Advanced Very High Resolution Radiometer imagery, Int. J. Climatol., 23, 1023-1044, 2003.

King, M. D.: Determination of the Scaled Optical Thickness of Clouds from Reflected Solar Radiation Measurements, J. Atmos. Sci., 44, 1734-1751, 1987.
King, M. D., Tsay, S. C., Platnick, S. E., Wang, M., and Liou, K. N.: Cloud retrieval algorithms for MODIS: Optical thickness, effective particle radius, and thermodynamic phase, MODIS Algorithm Theoretical Basis Document, ATBD-MOD-05, 78 pp. 1997.

Knap, W. H., C.-Labonnote, L., Brogniez, G., and Stammes, P.: Modeling total and polarized reflectances of ice clouds: evaluation by means of POLDER and ATSR-2 measurements, Appl. Opt., 44, 4060-4073, 2005.

Kristjánsson, J. E., Edwards, J. M., and Mitchell, D. L.: Impact of a new scheme for optical properties of ice crystals on climates of two GCMs, J. Geophys. Res., 105, 10063-10080, 2000.

L' Ecuyer, T. S., Gabriel, P., Leesman, K., Cooper, S. J., and Stephens, G. L.: Objective Assessment of the Information Content of Visible and Infrared Radiance Measurements for Cloud Microphysical Property Retrievals over the Global Oceans. Part I: Liquid Clouds, J. Appl. Meteorol. Climatol., 45, 20-41, 2006.

Lawson, R. P., Baker, B., Pilson, B., and Mo, Q.: In situ obervations of the microphysical properties of wave, cirrus and avil clouds. Part II: cirrus clouds, J. Atmos. Sci., 63, 3186-3202, 2006.

Lawson, R. P., Pilson, B., Baker, B., Mo, Q., Jessen, E., Pfister, L., and Bui, P.: Aircraft measurments of microphysical properties of subvisible cirrus in the tropical tropopause layer, Atmos. Chem. Phys., 8, 1609-1620, 2008,

http://www.atmos-chem-phys.net/8/1609/2008/.

Liou, K.-N.: Influence of Cirrus Clouds on Weather and Climate Processes: A Global Perspective, Mon. Weather Rev., 114, 1167-1199, 1986.

Liou, K. N. and Takano, Y.: Light scattering by nonspherical particles: remote sensing and climatic implications, Atmos. Res., 31, 271-298, 1994.

Liou, K. N.: An Introduction to Atmospheric Radiation, Academic Press, 583 pp., 2002.

Lohmann, U. and Roeckner, E.: Influence of cirrus cloud radiative forcing on climate and climate sensitivity in a general circulation model, J. Geophys. Res., 100, 16305-16324, 1995.

Macke, A., Mishchenko, M. I., Muinonen, K., and Carlson, B. E.: Scattering of light by large nonspherical particles: ray-tracing approximation versus T-matrix method, Opt. Lett, 20, 1934-1936, 1995.

Macke, A., Mishchenko, M. I., and Cairns, B.: The influence of inclusions on light scattering by large ice particles, J. Geophys. Res, 101, 23311-23316, 1996a.

Macke, A., Mueller, J., and Raschke, E.: Single Scattering Properties of Atmospheric Ice Crystals, J. Atmos. Sci., 53, 2813-2825, 1996b.

McFarquhar, G. M. and Heymsfield, A. J.: Microphysical Characteristics of Three Anvils Sampled during the Central Equatorial Pacific Experiment, J. Atmos. Sci., 53, 2401-2423, 1996.

McFarquhar, G. M., Heymsfield, A. J., Spinhirne, J., and Hart, B.: Thin and Subvisual Tropopause Tropical Cirrus: Observations and Radiative Impacts, J. Atmos. Sci., 57, 1841-1853, 2000.

McFarquhar, G. M.: Comments on "Parametrization of effective sizes of cirrus-cloud particles and its verification against observations" by Zhain Sun andLawrie Rikus (October B, 1999, 125,307-305), Q. J. Roy. Meteor. Soc., 127, 261-265, 2001.

McFarquhar, G. M., Yang, P., Macke, A., and Baran, A. J.: A new parameterization of single scattering solar radiance properties for tropical anvils using oberved ice crystal size and shape distribu- 
tions, J. Atmos. Sci., 59, 2458-2478, 2002.

Miller, S. D., Hawkins, J. D., Kent, J., Turk, F. J., Lee, T. F., Kuciauskas, A. P., Richardson, K., Wade, R., and Hoffman, C.: NexSat: Previewing NPOESS/VIIRS Imagery Capabilities, Bull. Amer. Meteor. Soc., 87, 433-446, 2006.

Minnis, P., Liou, K. N., and Takano, Y.: Inference of Cirrus Cloud Properties Using Satellite-observed Visible and Infrared Radiances. Part I: Parameterization of Radiance Fields, J. Atmos. Sci., 50, 1279-1304, 1993.

Mishchenko, M. I., Rossow, W. B., Macke, A., and Lacis, A. A.: Sensitivity of cirrus cloud albedo, bidirectional reflectance and optical thickness retrieval accuracy to ice particle shape, J. Geophys. Res., 101, 16973-16986, 1996.

Mishchenko, M. I., Cairns, B., Kopp, G., Schueler, C. F., Fafaul, B. A., Hansen, J. E., Hooker, R. J., Itchkawich, T., Maring, H. B., and Travis, L. D.: Accurate Monitoring of Terrestrial Aerosols and Total Solar Irradiance: Introducing the Glory Mission, B. Am. Meteor. Soc., 88, 677-691, 2007.

Nakajima, T. and King, M. D.: Determination of the Optical Thickness and Effective Particle Radius of Clouds from Reflected Solar Radiation Measurements. Part I: Theory, J. Atmos. Sci., 47, 1878-1893, 1990.

Oreopoulos, L. and Davies, R.: Plane Parallel Albedo Biases from Satellite Observations. Part I: Dependence on Resolution and Other Factors, J. Climate, 11, 919-932, 1998.

Platnick, S., King, M. D., Ackerman, S. A., Menzel, W. P., Baum, B. A., Riedi, J. C., and Frey, R. A.: The MODIS cloud products: algorithms and examples from Terra, IEEE T. Geosci. Remote Sens., 41, 459-473, 2003.

Ramanathan, V., Cess, R. D., Harrison, E. F., Minnis, P., Barkstrom, B. R., Ahmad, E., and Hartmann, D.: Cloud-Radiative Forcing and Climate: Results from the Earth Radiation Budget Experiment, Science, 243, 57-63, 1989.

Ramaswamy, V. and Ramanathan, V.: Solar Absorption by Cirrus Clouds and the Maintenance of the Tropical Upper Troposphere Thermal Structure, J. Atmos. Sci., 46, 2293-2310, 1989.

Riedi, J., Marchant, B., Platnick, S., Baum, B., Thieuleux, F., Oudard, C., Parol, F., Nicolas, J. M., and Dubuisson, P.: Cloud thermodynamic phase inferred from merged POLDER and MODIS data, Atmos. Chem. Phys. Discuss, 7, 14103-14137, 2007.

Roebeling, R. A., Feijt, A. J., and Stammes, P.: Cloud property retrievals for climate monitoring: Implications of differences between Spinning Enhanced Visible and Infrared Imager (SEVIRI) on METEOSAT-8 and Advanced Very High Resolution Radiometer (AVHRR) on NOAA-17, J. Geophys. Res., 111, D20210, doi:10.1029/2005JD006990, 2006.

Rossow, W. B. and Schiffer, R. A.: Advances in Understanding Clouds from ISCCP, Bull. Amer. Meteor. Soc., 80, 2261-2287, 1999.

Salomonson, V. V., Barnes, W. L., Maymon, P. W., Montgomery, H. E., and Ostrow, H.: MODIS: advanced facility instrument for studies of the Earth as asystem, IEEE T. Geosci. Remote Sens., 27, 145-153, 1989.

Sassen, K., Wang, Z., and Liu, D.: The global distribution of cirrus clouds from CloudSat/CALIPSO measurements, J. Geophys. Res., 113, D00A12, doi:10.1029/2008JD009972, 2008.

Schlimme, I., Macke, A., and Reichardt, J.: The impact of ice crystal shapes, size distribution, and spatial structure of crrius clouds on solar radiave fluxes, J. Atmos. Sci., 62, 2274-2283, 2005

Schmit, T. J., Gunshor, M. M., Menzel, W. P., Gurka, J. J., Li, J., and Bachmeier, A. S.: INTRODUCING THE NEXT-GENERATION ADVANCED BASELINE IMAGER ON GOES-R, B. Am. Meteor. Soc., 86, 1079-1096, 2005.

Sherwood, S. C.: Detection of faceted crystals in deep convective clouds via the antisolar peak, Geophys. Res. Lett., 110, D14210, doi:10.1029/2004JD005549, 2005.

Stephens, G. L., Tsay, S.-C., Stackhouse, P. W., and Flatau, P. J.: The Relevance of the Microphysical and Radiative Properties of Cirrus Clouds to Climate and Climatic Feedback, J. Atmos. Sci., 47, 1742-1754, 1990.

Takano, Y. and Liou, K.-N.: Solar Radiative Transfer in Cirrus Clouds. Part I: Single-Scattering and Optical Properties of Hexagonal Ice Crystals, J. Atmos. Sci., 46, 3-19, 1989.

van de Hulst, H. C.: Light Scattering by Small Particles, Light Scattering by Small Particles, John Wiley \& Sons, New York, USa, 470 pp., 1957.

van de Hulst, H. C.: Multiple light scattering. Tables, formulas and applications, New York: Academic Press, 436 pp., 1980.

Wang, P.-H., Minnis, P., McCormick, M. P., Kent, G. S., and Skeens, K. M.: A 6-year climatology of cloud occurrence frequency from Stratospheric Aerosol and Gas Experiment II observations (1985-1990), J. Geophys. Res., 101, 29407-29429, 1996.

Wei, H., Yang, P., Li, J., Baum, B. A., Huang, H. L., Platnick, S., $\mathrm{Hu}$, Y., and Strow, L.: Retrieval of semitransparent ice cloud optical thickness from Atmospheric Infrared Sounder (AIRS) measurements, IEEE Transactions on Geoscience and Remote Sensing, 42, 2254-2267, 2004.

Weickmann, H. K.: Die Eisphase in der Atmosphäre (The Ice Phase in the Atmosphere), Royal Aircraft Establishments, 96 pp., 1947.

Wendisch, M., Yang, P., and Pilewskie, P.: Effects of ice crystal habit on thermal infrared radiative properties and forcing of cirrus, J. Geophys. Res., 112, doi:10.1029/2006JD007899, D08201, 2007

Wu, D. L., Jiang, J. H., and Davis, C. P.: EOS MLS cloud ice measurements and cloudy-sky radiative transfer model, IEEE T. Geosci. Remote Sens., 44, 1156-1165, 2006.

Wylie, D. P. and Menzel, W. P.: Eight Years of High Cloud Statistics Using HIRS, J. Climate, 12, 170-184, 1999.

Yang, P. and Liou, K. N.: Geometric-optics-integral-equation method for light scattering by nonspherical ice crystals, Appl. Opt., 35, 6568-6584, 1996.

Yang, P., Baum, B. A., Heymsfield, A. J., Hu, Y. X., Huang, H. L., Tsay, S. C., and Ackerman, S.: Single-scattering properties of droxtals, JQSRT, 79, 1159-1169, 2003.

Yang, P., Zhang, L., Hong, G., Nasiri, S. L., Baum, B. A., Huang, H.-L., King, M. D., and Platnick, S.: Differences Between Collection 4 and 5 MODIS Ice Cloud Optical/Microphysical Products and Their Impact on Radiative Forcing Simulations, IEEE T. Geosci. Remote Sens., 45, 2886-2899, 2007.

Yang, P., Hong, G., Kattawar, G. W., Minnis, P., and Hu, Y.: Uncertainties Associated With the Surface Texture of Ice Particles in Satellite-Based Retrieval of Cirrus Clouds: Part II-Effect of Particle Surface Roughness on Retrieved Cloud Optical Thickness and Effective Particle Size, IEEE T. Geosci. Remote Sens. 46, 1948-1957, 2008.

Yue, Q., Liou, K. N., Ou, S. C., Kahn, B. H., Yang, P., and Mace, G. 
G.: Interpretation of AIRS data in thin cirrus atmospheres based on a fast radiative transfer model, J. Atmos. Sci., 64, 3827-3842, 2007.

Zhang, M. H., Lin, W. Y., Klein, S. A., Bacmeister, J. T., Bony, S., Cederwall, R. T., Del Genio, A. D., Hack, J. J., Loeb, N. G., and Lohmann, U.: Comparing clouds and their seasonal variations in 10 atmospheric general circulation models with satellite measurements, J. Geophys. Res, 110, D15S02, doi:10.1029/2004JD005021, 2005.
Zhang, Z., Yang, P., Kattawar, G. W., Tsay, S.-C., Baum, B. A., $\mathrm{Hu}$, Y., Heymsfiel, A. J., and Reichardt, J.: Geometrical-Optics Solution to Light Scattering by Droxtal Ice Crystals, Appl. Opt., 43, 2490-2499, 2004. 